\title{
EL MALTRATO A MENORES EN LA PROVINCIA DE ALICANTE EN EL PERIODO 1980 -1997
}

DRA. M DOLORES DÍEZ GARCÍA

Prof. E.U. de Trabajo Social. Universidad de Alicante.

DR. SERGIO QUESADA RETTSCHLAG

Prof. E.U. de Trabajo Social. Universidad de Alicante.

$M^{\mathrm{a}}$ DOLORES SALA BONMATÍ

Trabajadora Social.

\section{RESUMEN}

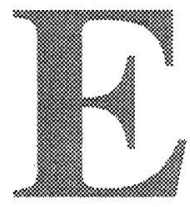

n los últimos años se está tomando conciencia acerca de un problema que necesita de la intervención de la Sociedad y, en particular, de los profesionales que actúan en el campo social. Nos estamos refiriendo al tratamiento de situaciones problemáticas relacionadas con los malos tratos a menores. Se requiere una intervención que contemple las tres áreas de actuación: individual, grupal y comunitaria, con especial atención a la prevención de estos problemas.

Este hecho nos ha llevado a plantearnos la realización de un estudio empírico que nos permita detectar el estado real del problema en un estrato concreto de la sociedad, a la vez que sustentara cuantas conclusiones y posibles vías de actuación se pudieran realizar a partir de dicho conocimiento.

\section{PALABRAS CLAVE}

Maltrato, menores, físico, emocional, prevención.

\section{INTRODUCCIÓN}

El tema de los malos tratos en los menores es una cuestión desgraciadamente de creciente actualidad cuya única cara positiva radica en la posibilidad de concienciar a la sociedad, a los agentes sociales y a la Administración, para que, aunando esfuerzos, la situación de estos niños pueda mejorar, al mismo tiempo que se desarrolla una labor más eficaz en los aspectos de prevención. 
Cuando se habla del maltrato, habitualmente (tal vez por la influencia de los medios de comunicación, que a menudo nos presentan los casos más dramáticos y escabrosos de maltrato hacia menores), pensamos en el niño que presenta cualquier tipo de agresión física, pero no podemos olvidar que existe otro tipo de agresión que no se detecta tan fácilmente, y puede crear un daño tal vez mayor. Nos estamos refiriendo a las agresiones psicológicas, «es fácil considerar que se puede dar maltrato psicológico sin que haya maltrato físico; pero no es tan sencillo separarlo a la inversa: cuando hay maltrato físico se puede afirmar que casi siempre hay daño psicológico»'. Se está proponiendo el concepto de maltrato emocional por ser una concepción más amplia, y así evitar que exista una separación entre la terminología referida al maltrato físico y psicológico.

El mismo autor señala en el trabajo citado que el maltrato emocional puede ser entendido como «aquellas conductas dirigidas intencionalmente por un adulto hacia otra persona (niño o adulto) que producen en ésta daño interno a través de sentimientos negativos (desvalorización, desestima) hacia su propia persona sin justificación ni necesidad».

Es importante también reseñar que en los primeros años de vida cualquier tipo de maltrato tiene unas consecuencias que revisten mayor gravedad, debido a la fragilidad y la indefensión del niño. Según diferentes autores, «el $60 \%$ de las muertes que ocurren por conducta abusiva paterna y el $50 \%$ de los casos que resultan con daños permanentes, principalmente por lesiones en la cabeza, se producen entre los menores de 2 años» ${ }^{2}$, igualmente, otro dato apunta a que «en nuestro país las muertes producidas por maltrato se detectan generalmente entre niños de menos de 3 años. Por tanto, el maltrato en los primeros años de vida representa un grave peligro para la vida del niño, por lo que se debe desarrollar una labor en los diversos aspectos, pero, principalmente, en el aspecto informativo, y sobre todo en el ámbito de prevención»3.

La legislación vigente acerca de los derechos del menor, Ley 1/96 en su Título I, referente a los derechos de los menores (al honor, a la intimidad, a la información, a la libertad ideológica, de participación,

BUENO BUENO, A. Aspectos psicológicos del maltrato infantil. III Jornadas de reflexión Menores. 28-febrero-1997. Escuela Universitaria de Trabajo Social. Pág. 2 y 3.

2 NEWBERG. (1.982). Citado en: El maltrato fisico y emocional en la primera infancia. Bienestar y Protección Infantil. Edit. F.A.P.M.I. (Federación de A sociaciones para la Prevención del Maltrato Infantil). $\mathrm{N}^{\circ} 4$ diciembre-96. Madrid.

3 CASCALES HILLA, C. Derechos del niño y protección al menor. III Jornadas de reflexión Menores. 28-febrero-1997. Escuela Universitaria de Trabajo Social. Pág. 3. 
a ser oído, a expresarse libremente....), y en su Título II, de las actuaciones en situación de desprotección social del menor e instituciones de protección de menores, incorpora las nuevas necesidades de una sociedad que a la vez que evoluciona es cambiante en sus demandas.

A su vez, «el sistema de protección social del menor está encaminado a prevenir $e$ intervenir en situaciones que comporten riesgo o desamparo de estos menores, actuando en cada caso con las medidas correspondientes, bien desde los servicios sociales de base (ayudas puntuales) o bien en la asunción de la tutela en los casos de desamparo» ${ }^{4}$.

Otro factor importante a tener en cuenta, a la hora de analizar los malos tratos, es la situación de riesgo que afecta tanto a los menores, como a las familias donde está integrado el menor maltratado. En estas situaciones de riesgo se puede destacar, en líneas generales, los problemas que afectan a un porcentaje alto de estas familias, dentro de las que padecen riesgo de carácter social: familias monoparentales, la mayoría numerosas, con vivienda precaria, de bajo nivel económico, convertido, en algunos casos, en situaciones de pobreza (obligando a sus miembros a practicar la mendicidad), subempleo y bajo nivel educativo. Otro tipo de causa, en estas conductas, son las asociadas al consumo de alcohol y otras drogas por llevar coligado el modo violento de los que las consumen. Este compendio de problemas hace que en familias en las que no se asumen situaciones de desequilibrio se desarrolle la violencia (física y/o emocional) hacia los menores o hacia la totalidad de sus miembros.

Todos estos motivos demuestran la necesidad de una mayor concienciación sobre un problema cuya solución requiere la participación de toda la sociedad y, más concretamente, de los profesionales que actúan en el campo social, dentro de los cuales los trabajadores sociales tienen un papel fundamental en el tratamiento de estas situaciones-problemas. Se requiere, pues, por parte de estos profesionales, una intervención que contemple las tres áreas de actuación: individual, grupal y comunitaria, y que a su vez preste una especial atención a la prevención.

Este conjunto de consideraciones nos llevaron a plantearnos la realización de un estudio empírico que nos permitiera conocer el estado real del problema en el estrato social objeto de estudio, a la vez que sustentara cuantas conclusiones y comentarios pudiéramos realizar a partir de dicho conocimiento.

4 RODRÍGUEZ BONGIL, J.El drama del menor en España. Ediciones B.J.A. 1993 Barcelona. Pág. 31. 
Por ello, la finalidad de este estudio es múltiple. Por una parte, nos interesa concretar qué tipos de maltrato se dan con mayor frecuencia en los menores de nuestra comunidad, qué edades tienen estos niños y cómo les afecta física y/o emocionalmente el problema. Otro objetivo es conocer la relación que tiene el menor con su familia de origen, la existencia de otros hermanos, la situación de los mismos y el lugar de residencia (si es la residencia familiar o no, en régimen de acogimiento, o si reside en un centro de acogida).

\section{METODOLOGÍA}

Para la realización de nuestro estudio, escogimos dentro del Servicio de Programas de Asuntos Sociales, la Sección de Medidas Judiciales y Reforma de Menores de la antigua Consellería de Trabajo y Asuntos Sociales en su delegación de Alicante (de cuyos miembros queremos hacer público reconocimiento por su amabilidad y facilidades dadas). Seleccionamos una muestra aleatoria de 100 expedientes de menores, de entre los correspondientes a los diecisiete últimos años. Este tamaño de muestra, bajo la hipótesis de $\mathrm{p}=50 \%$, conlleva un margen de confianza del 95 '5\%.

Después de obtener y clasificar los datos, se realizó un análisis estadístico de ellos, cuyos resultados vienen sintetizados en los gráficos que presentamos, así como en los comentarios sobre los mismos. El estudio se ha centrado en conocer aspectos generales del menor y de los padres biológicos, e igualmente aspectos concretos de los malos tratos de los que son víctimas estos menores.

En consecuencia, además de los datos sociológicos relativos a los menores objeto de estudio, y de los motivos por los que ingresan en un centro, se abordan problemas que les afectan directa e indirectamente. También se han incluido las tipologías tanto de la madre biológica como del padre biológico, su situación sanitaria, sociolaboral y estado civil, entre otros.

\section{III.RESULTADOS}

\section{3.l. Aspectos generales del menor.}

En función de una mayor facilidad interpretativa, describiremos, con un carácter eminentemente gráfico, los principales resultados obtenidos. Comenzaremos, para ello, con cuestiones relativas al menor. 


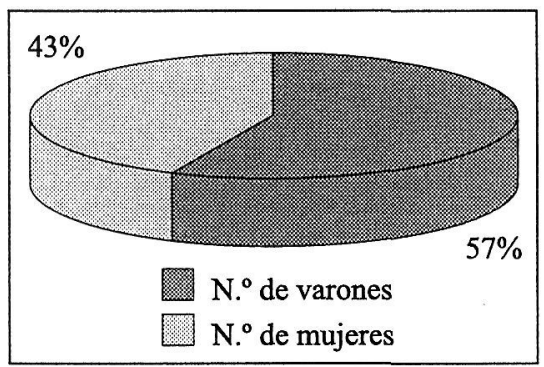

GRÁFICO 1: Distribución de los menores por sexo.

En el Gráfico 1, observamos que el sexo no parece ser determinante en los malos tratos al menor, a pesar de que existe un diferencial de porcentaje entre varones y mujeres de un $14 \%$.

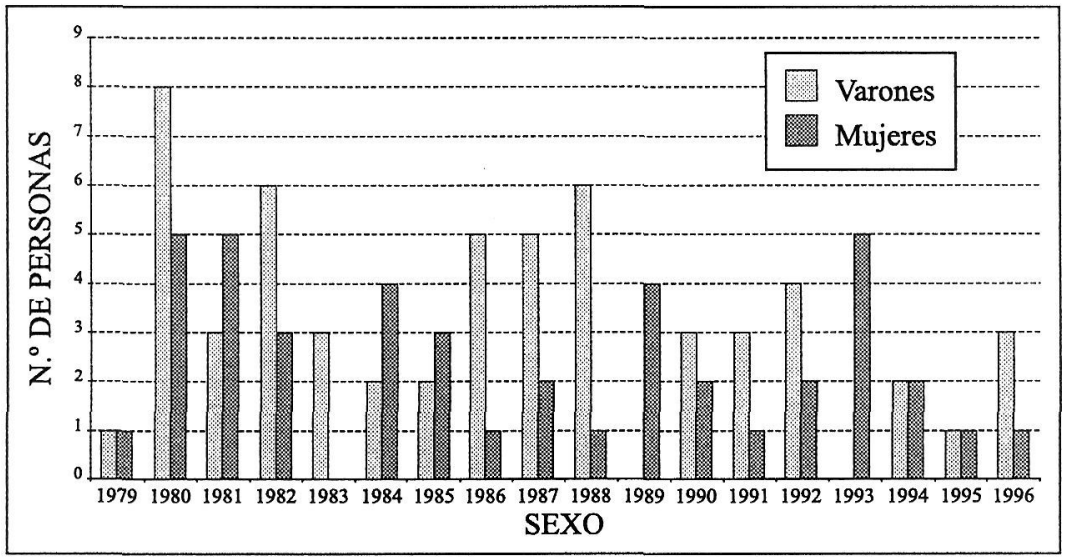

GRÁFICO 2: Distribución del menor por edad y sexo.

En el Gráfico 2, relativo al año de nacimiento y sexo de los menores objeto de malos tratos, podemos apreciar:

- Que en el año 1979 existe un $n^{\circ}$ mínimo atípico de malos tratos cuyas causas, si bien podrían estar asociadas a la edad, habría realmente que determinarlas. A partir de 1980 hay una ligera disminucion global de los mismos.

- Determinados años presentan una gran diferencia a favor de un sexo, destacando 1989 y 1993 en los que los malos tratos afectaron solamente a las mujeres.

- Los menores de 3 años presentan situación de maltrato en un 10\% de los casos, sin diferencias importantes a favor de un sexo. 


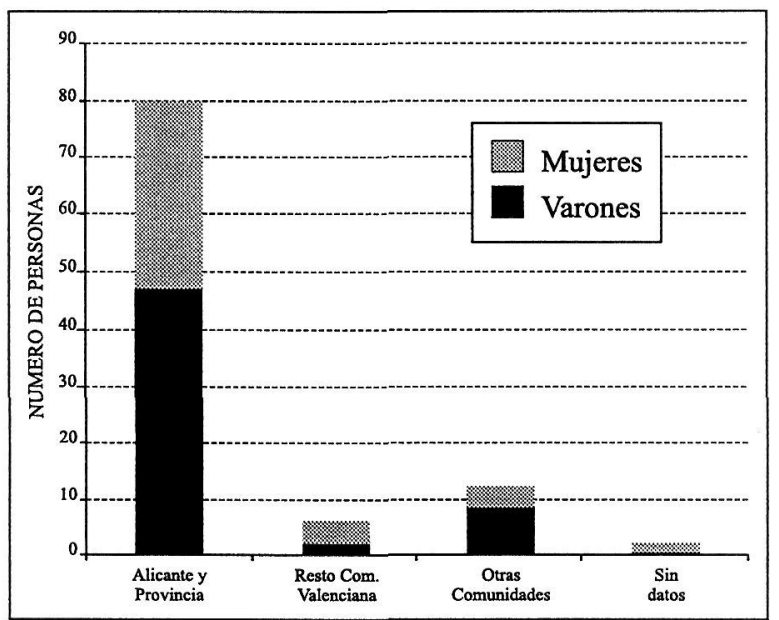

GRÁFICO 3: Localidad de nacimiento y sexo del menor

El Gráfico 3 muestra la existencia de un mayor número de menores nacidos en Alicante y provincia atribuible a que el estudio ha sido elaborado a partir de los datos recogidos en esta provincia. Se observa la existencia de menores de otras provincias como Madrid, Barcelona, Málaga, etc., debido a la movilidad geográfica de algunas familias.

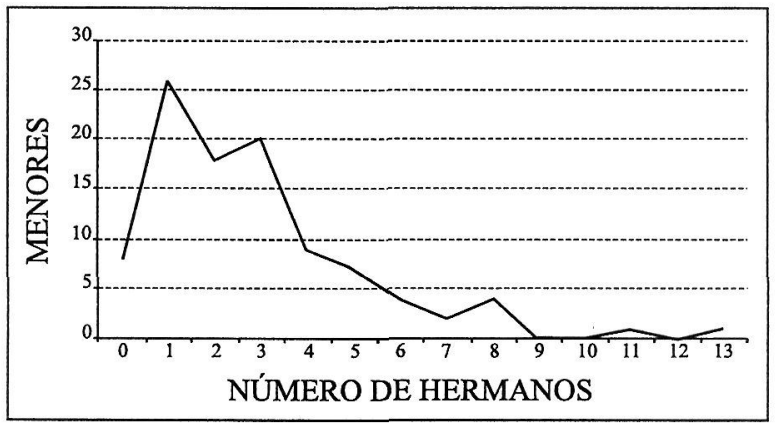

GRÁFICO 4: Número de hermanos del menor.

En el Gráfico 4, podemos apreciar como un $92 \%$ de los menores estudiados tiene algún hermano, entre ellos destaca como máxima frecuencia el valor 26, correspondiente a aquellos menores que tienen un solo hermano. Por otra parte, entre uno y tres hermanos se encuentra el $64 \%$ de la muestra, mientras que con más de cuatro hermanos se halla el $19 \%$ de los menores. El máximo valor corresponde a un niño que cuenta con trece hermanos. 


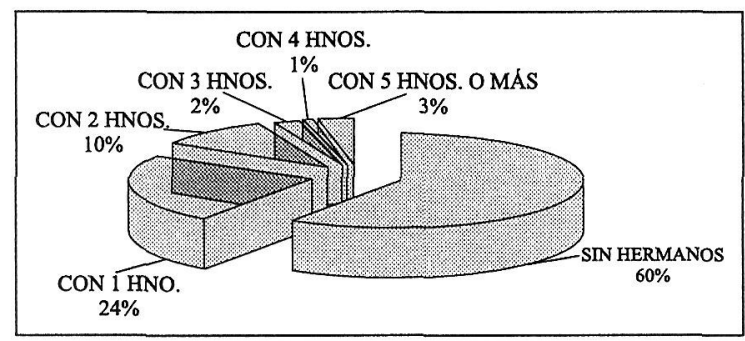

GRÁFICO 5: Hermanos del menor con medidas de protección.

Nos interesaba conocer no sólo si estos menores tenían otros hermanos sino, además, cuál era su situación. El Gráfico 5 refleja que un $60 \%$ de los menores no tienen hermanos con medidas de protección. Existe un $24 \%$ de menores con un hermano atendido en alguna institución. Llama la atención la existencia de un menor, que de trece hermanos tiene nueve con expediente abierto.

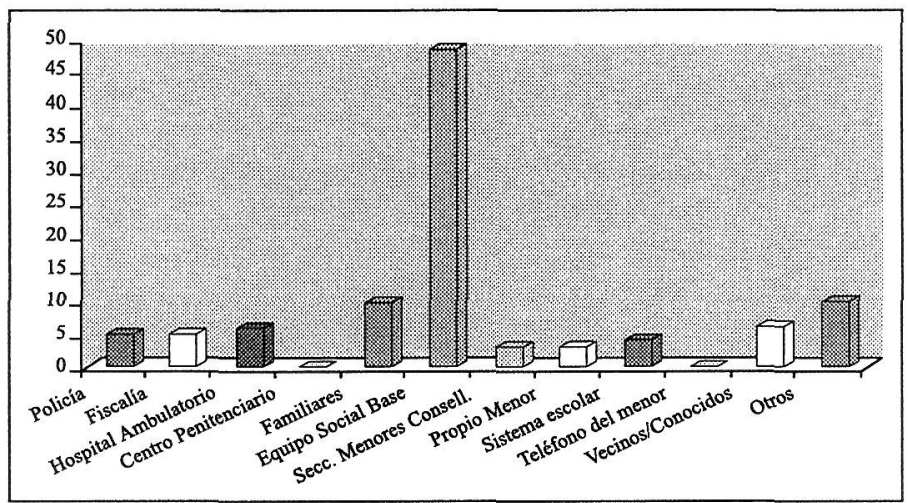

GRÁFICO 6: Vía de detección.

Los resultados relativos a la vía de detección del problema se aprecian en el Gráfico 6, indicando las personas, los centros o instituciones donde llega el problema que sufre el menor, derivando el caso cuando no se tienen competencias para una primera actuación. Destaca sobre todos los demás el Equipo Social de Base Municipal con un $48 \%$ de casos detectados. Curiosamente, aparece un dato acerca de uno de los servicios de implantación reciente en esta ciudad, el teléfono del menor, con un porcentaje de utilización $(0 \%)$, posiblemente debido a la falta de información que el usuario tiene de su existencia.

Por otra parte, era importante conocer las posibles vías de entrada de estos menores. Este hecho se muestra en el Gráfico 7 donde queda reflejado que el $61 \%$ de los casos entran a través de la Sección de la 


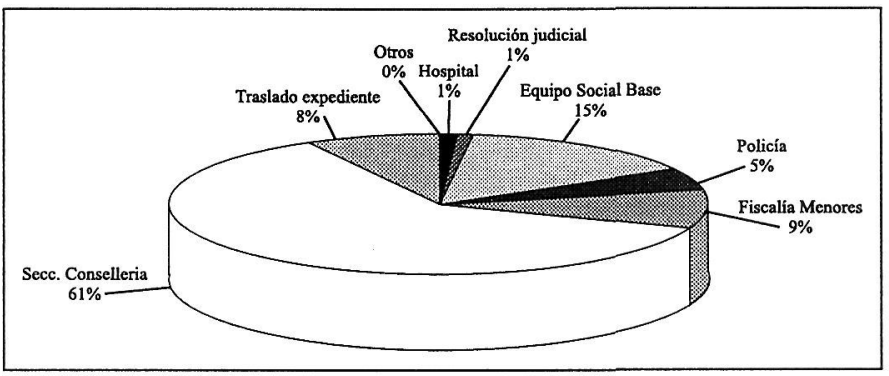

GRÁFICO 7: Vía de entrada.

Consellería, seguido en un 15\% por el Equipo Social de base, mientras que la entrada a través de un hospital o por resolución judicial es un porcentaje muy pequeño. Esto nos hace intuir que o bien no se puede hablar de un número alto de menores que sufran castigo físico severo o bien, si existen, en estos casos no se realiza la tramitación directa al hospital, sino que se derivan a las dos vías de entrada citadas. Comparando los Gráficos 6 y 7 deducimos que, de los detectados por el Equipo Social Base, sólo un 15\% de los casos es tramitado por el propio equipo para su posterior estudio y resolución, derivando un $33 \%$ de los casos hacia la Sección de la Consellería relativa al menor.

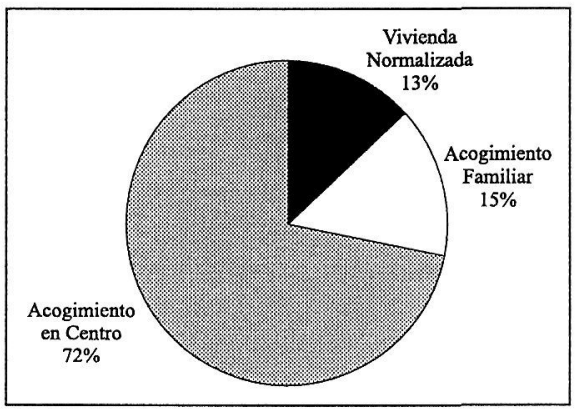

GRÁFICO 8: Tipo de vivienda del menor.

En el Gráfico 8 es fácil observar que la mayoría de los niños, un $72 \%$, están ingresados en Centros de acogimiento, esto indica que, aunque existen más recursos, el tipo de vivienda más utilizada donde se acoge al menor es la de una institución.

En cuanto a datos relativos a su educación, el Gráfico 9 nos indica un hecho importante, que la mayoría de menores, aun presentando problemas, tienen un grado de escolarización medio. La mayor frecuencia, un $63 \%$, corresponde a los que estudian E.G.B./E.S.O./F.P. $\mathrm{y}$, en cuanto al sistema escolar, destaca con un $43 \%$ la normalidad en 


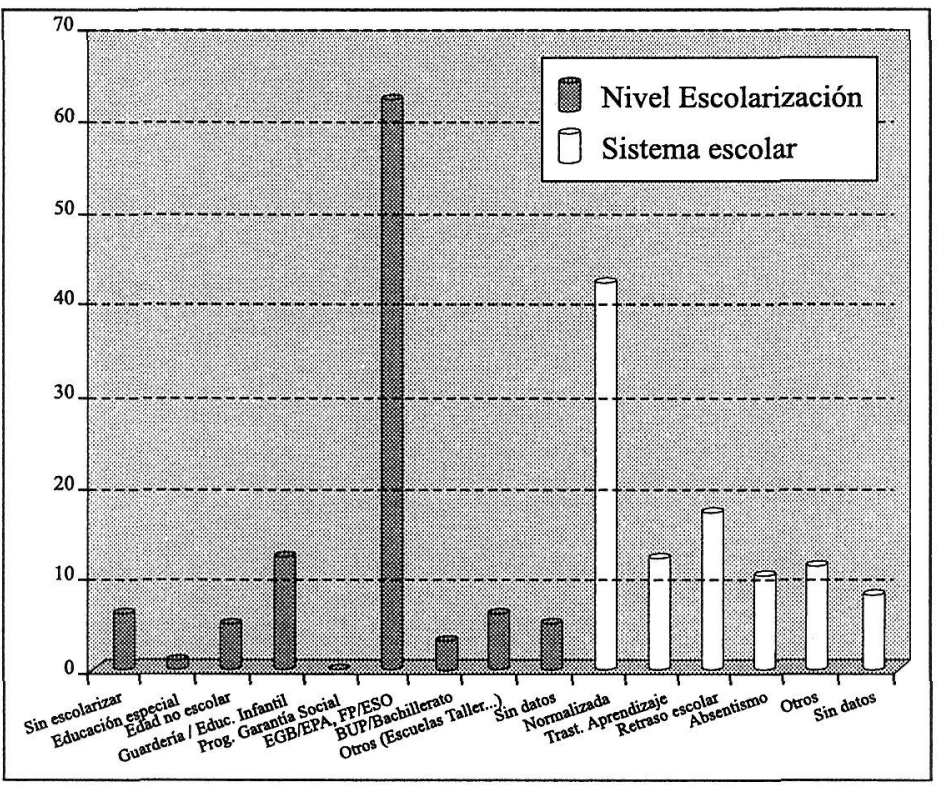

GRÁFICO 9: Datos de Educación.

el sistema escolar, seguido, a gran distancia, por alumnos con retraso escolar manifiesto en un $18 \%$ de casos o transtornos de aprendizaje en un $12 \%$.

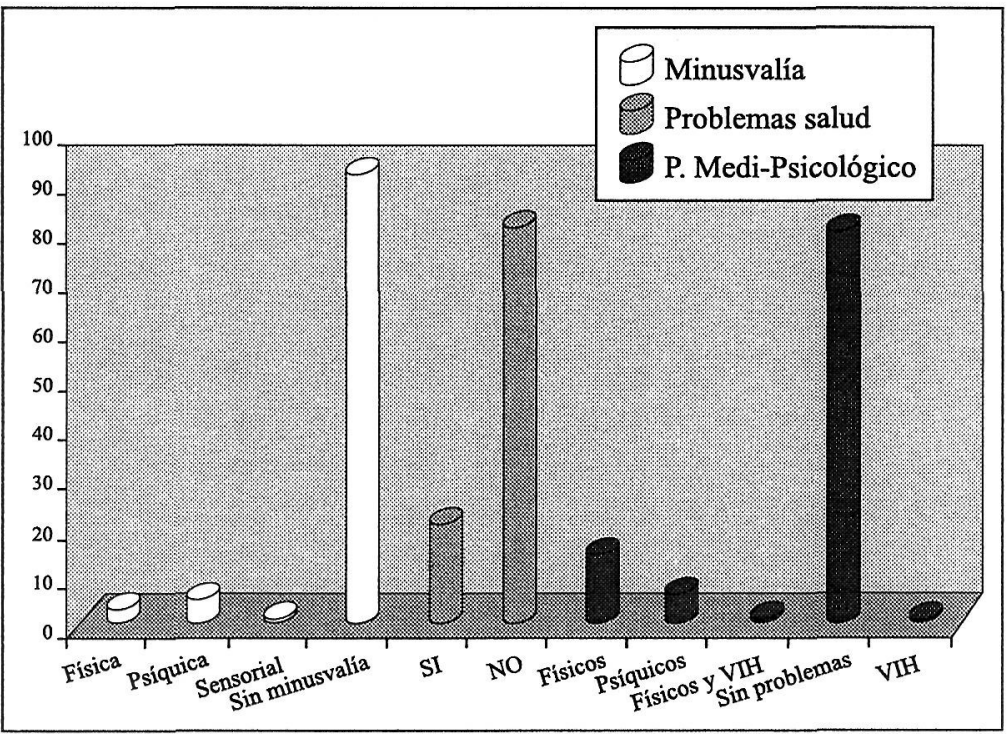

GRÁFICO 10: Problemas de salud de los menores. 
Por último, en el Gráfico 10 observamos que, afortunadamente, los menores no presentan en su mayoría problemas sanitarios, ni problemas de minusvalía, sólo existe un $28 \%$ que presenta problemas de salud, de los cuales el $18 \%$ corresponde a problemas físicos y el resto a problemas psíquicos.

\subsection{Aspectos generales de los padres biológicos.}

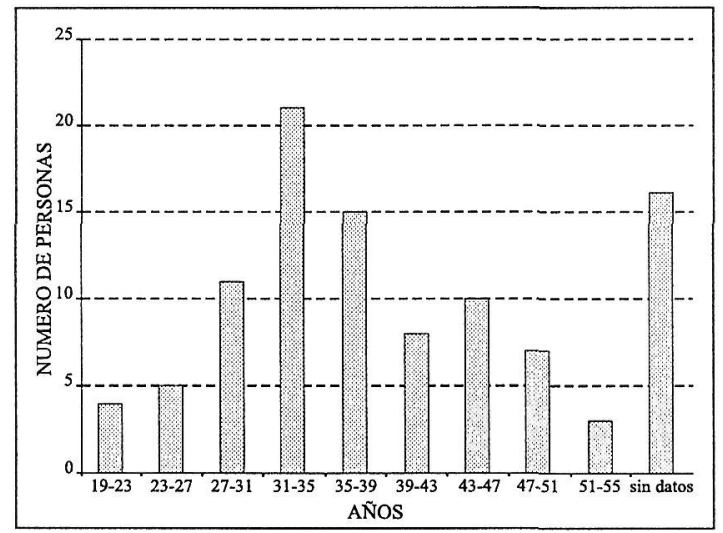

GRÁFICO 11: Edad de la madre biológica.

A partir de la tabla relativa al Gráfico 11, se ha obtenido 36 años como edad media de la madre biológica del menor, siendo el intervalo modal el comprendido entre 31 y 35 años. Análogamente, con la tabla del Gráfico 12, se obtuvo como edad media del padre biológico 43 años. Estos resultados indican que no es la juventud uno de los factores de mayor riesgo que suele aparecer en los padres que maltratan. Es de destacar el elevado porcentaje, un $30 \%$, de los padres de los que no se dispone de datos.

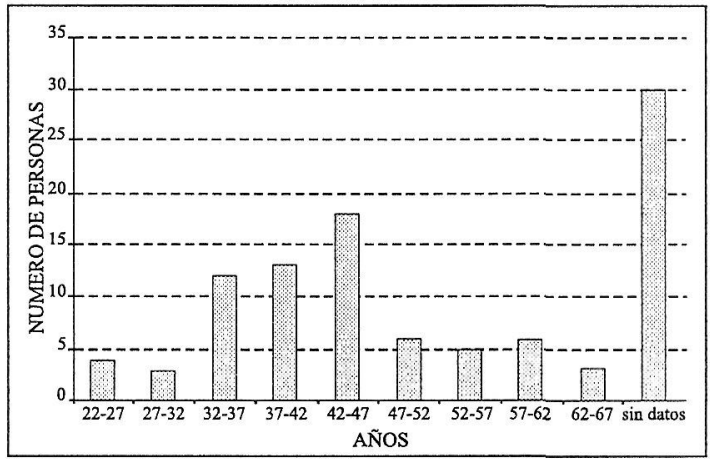

GRÁFICO 12: Edad del padre biológico 


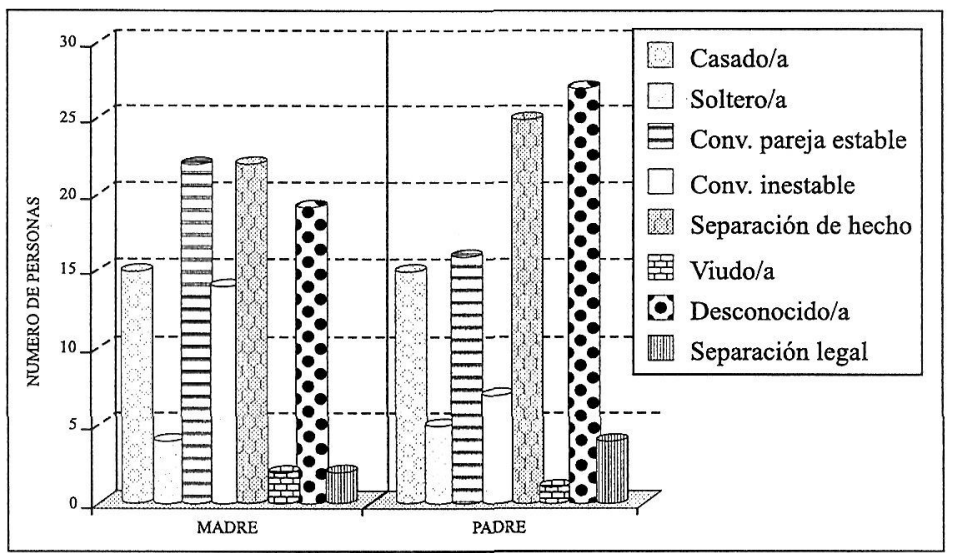

GRÁFICO 13: Estado civil del padre/madre biológicos.

El Gráfico 13 nos muestra que, en el caso concreto de la madre, existe el mismo número con separación de hecho, $22 \%$, que conviviendo con pareja estable. Respecto al padre, hemos encontrado que de un $27 \%$ de ellos se desconoce su estado civil, lo cual puede dar lugar a diferentes interpretaciones: o el padre no es necesariamente quien convive con la madre o éste no mantiene ningún contacto con los responsables de la guarda o custodia del menor. Le sigue en importancia los padres que tienen separación de hecho con un $24 \%$.

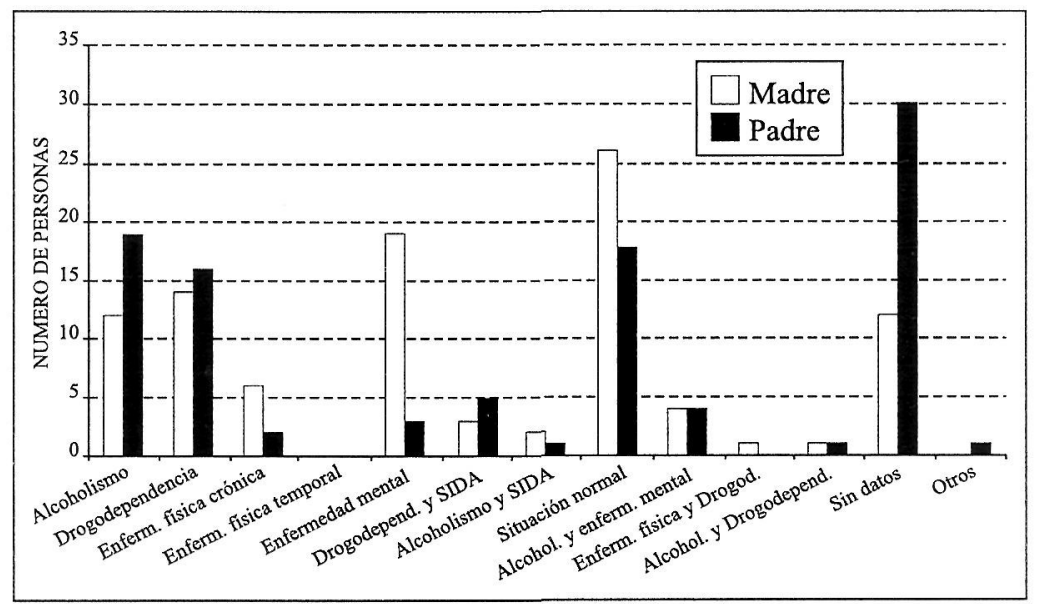

GRÁFICO 14: Situación sanitaria de los padres biológicos.

La situación sanitaria se aborda en el Gráfico 14. Pasamos a destacar la incidencia que pueden tener ciertas situaciones sanitarias en el comportamiento de los padres hacia los menores. 
- En el caso de la madre, existe un $26 \%$ en situación de normalidad, seguida en importancia en un $18 \%$ por las madres que padecen alguna enfermedad mental y alrededor de un $14 \%$ que son drogodependientes, lo cual crea un factor de riesgo añadido en los menores.

- En cuanto al padre, uno de los problemas más repetidos es el alcoholismo, con un $19 \%$, seguido de los drogodependientes en un $16 \%$, existiendo un alto porcentaje de expedientes, el $29 \%$, sin datos en este apartado. El sida no es una situación detectada en los casos estudiados.

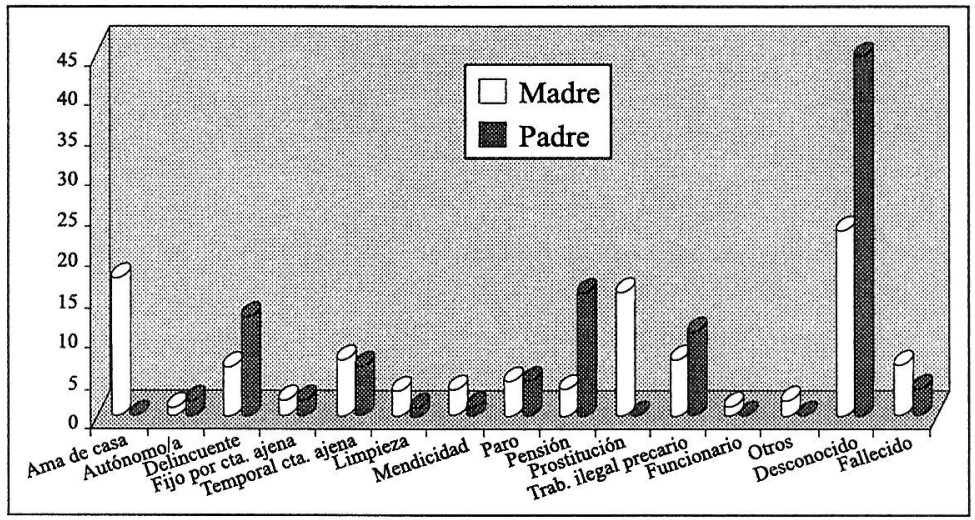

GRÁFICO 15: Situación laboral de los padres biológicos.

Respecto a la situación laboral de los padres biológicos, el dato más significativo, correspondiente al $44 \%$ de los expedientes y que se muestra en el Gráfico 15, es el desconocimiento de la situación laboral del padre, los demás valores nos indican que existe un mayor índice de pensionistas, trabajos ilegales y temporales por cuenta ajena, lo cual induce a pensar que el nivel económico familiar es bastante bajo. En la madre aparece un grupo, $20 \%$, cuya situación es la de ama de casa, en contraposición con las dedicadas a la prostitución que son el $18 \%$ de ellas. En el extremo opuesto encontramos el caso de los padres funcionarios como situación mínima. No existe una gran incidencia de mortalidad en los datos relativos a los padres, un $7 \%$ de las madres ha fallecido frente a un $3 \%$ de los padres del total de la muestra.

En cuanto a la vivienda, los Gráficos 16 y 17 muestran, como dato significativo a tener en cuenta, la normalidad, un $40 \%$ para las madres y un $55 \%$ para los padres, en el tipo de vivienda de los padres biológicos en la Comunidad Valenciana. Los acogimientos en algún centro asistencial, penitenciario o con familiares es mínimo. En el caso del 


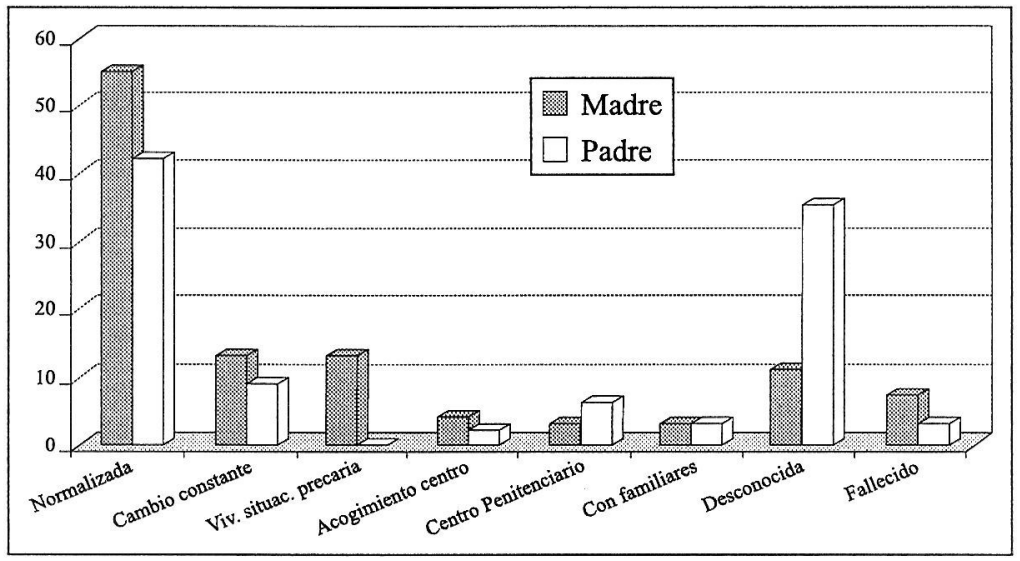

GRÁFICO 16: Tipo de vivienda de los padres biológicos.

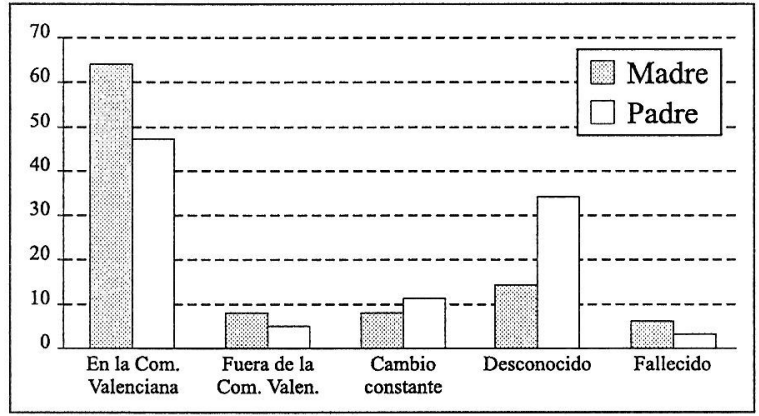

GRÁFICO 17: Domicilio de los padres biológicos.

padre vuelve a ser elevado, un $34 \%$, el porcentaje relativo al desconocimiento del lugar de residencia.

\subsection{Aspectos generales de los malos tratos en los menores.}

Siguiendo con otros aspectos importantes hemos estudiado los tipos de maltrato, la representación gráfica 18 señala este tipo de maltrato o abandono sufrido por los menores en Alicante y provincia, indicando además cuál es la tipología de maltrato más frecuente en los expedientes estudiados.

El gráfico descubre que en un $73 \%$ de los casos se da el abandono físico como causa de maltrato o como motivo de ingreso del menor en el sistema de protección. Este tipo de maltrato se desagrega en distintas situaciones apareciendo éstas de forma aislada o asociadas y con sus correspondientes porcentajes. 


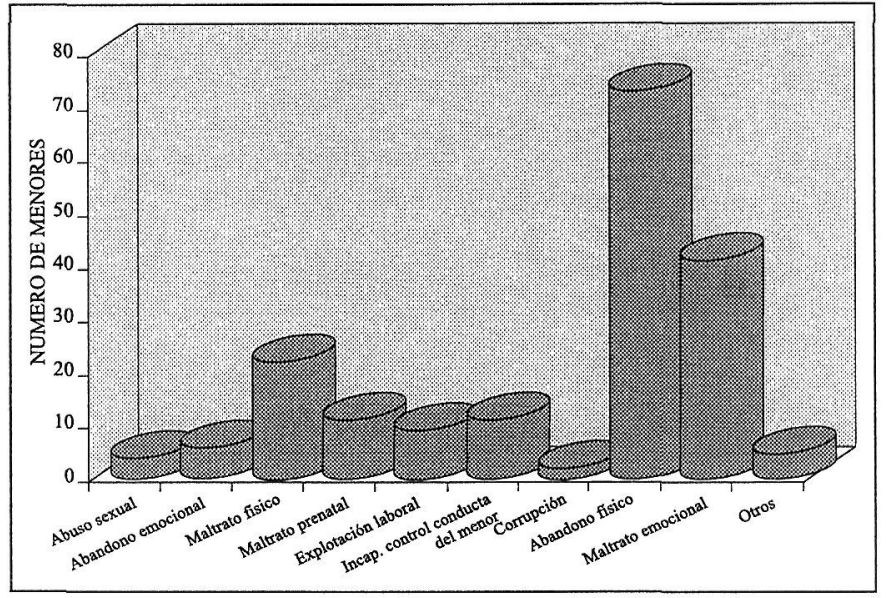

GRÁFICO 18: Comparativa del tipo de maltrato

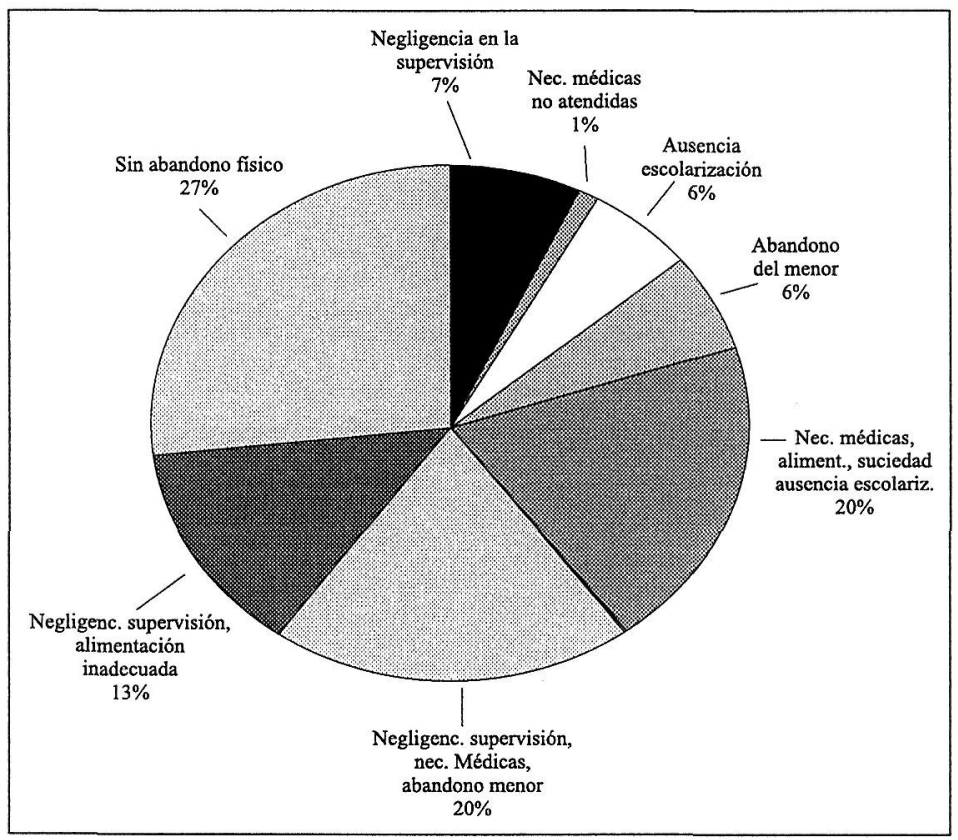

GRÁFICO 19: Abandono físico del menor.

- negligencia en la supervisión, 7\%,

- necesidades médicas - sanitarias no atendidas, $1 \%$,

- escasez o ausencia de escolarización, $6 \%$,

- abandono del menor en un lugar, 6\%,

- negligencia en la supervisión y alimentación, $13 \%$, 
- negligencia en la supervisión junto con necesidades médicas no atendidas y abandono del menor, $20 \%$,

- necesidades médicas no atendidas, alimentación inadecuada, suciedad muy llamativa y ausencia de escolarización, $20 \%$.

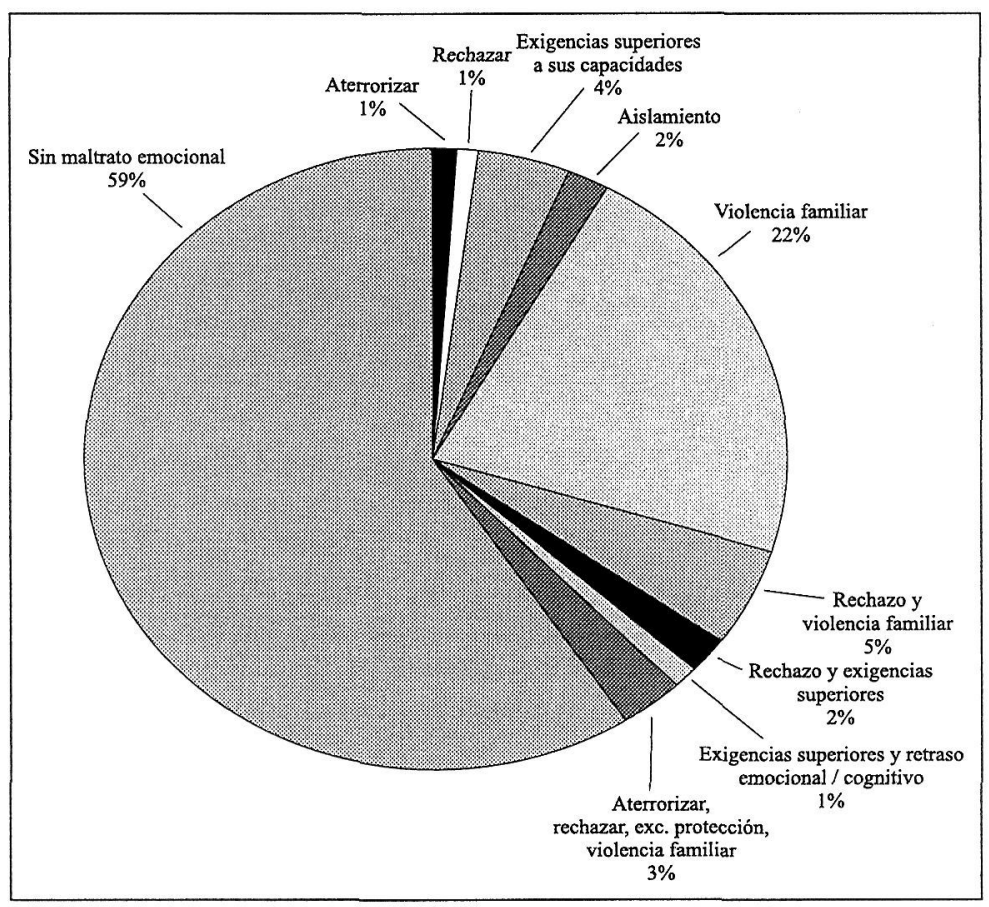

GRÁFICO 20: Maltrato emocional del menor.

Como segundo tipo del maltrato se refleja el emocional con un $41 \%$, que contempla las siguientes situaciones y porcentajes

- aterrorizar con un castigo extremo que le generará un miedo intenso, $1 \%$,

- rechazarlo, ridiculizarlo o insultarlo, $1 \%$,

- exigencias superiores a su capacidad, $4 \%$,

- aislamiento (privación de relaciones sociales), $2 \%$,

- violencia familiar, $22 \%$,

- rechazo y violencia familiar, $5 \%$,

- rechazo y exigencias superiores a su capacidad, $2 \%$,

- exigencias superiores a su capacidad con retraso en su desarrollo emocional y cognitivo, $1 \%$,

- aterrorizar, rechazar, excesiva protección junto con violencia familiar, $3 \%$. 
Al comprobar que los tipos de maltrato más comunes entre los menores eran el abandono físico y el maltrato emocional, se aplicó un test estadístico que permitiera analizar la independencia o relación entre estos dos caracteres. Concluimos, a un nivel del $5 \%$, que no se puede aceptar la hipótesis de Independencia, o lo que es lo mismo, que los menores que sufren abandono físico no tienen porqué recibir necesariamente un maltrato emocional.

\section{IV.CONCLUSIONES.}

A través de los resultados obtenidos en este estudio estamos en disposición de conocer más de cerca la problemática que afecta a los menores que sufren cualquier tipo de maltrato o abandono en nuestra provincia.

A primera vista, se puede decir que efectivamente influyen los diferentes factores de riesgo en la conducta de los padres maltratadores, ya que se han detectado como situaciones de riesgo las derivadas de enfermedades (alcoholismo, enfermedad mental, drogodependencias) o situaciones de bajo nivel económico, con trabajo precario o ilegal, así como problemas estructurales en la familia biológica.

En los datos referidos a los menores observamos que el sexo no es determinante en estas situaciones. Del estudio de los expedientes, se deduce que un $32 \%$ de niños tiene edades comprendidas entre 15 y 18 años, estando 10 de ellos sujetos a medidas de protección antes de 1990. En el otro extremo de la distribución por edades están los menores de 3 años, un 10\% del total, a los que se les ha abierto expediente en el año 96 . En cuanto al número de hermanos, existe un $39 \%$ con familia numerosa, siendo un hermano el hecho más común para un $26 \%$ de ellos. Si bien un $60 \%$ de los menores no tiene ningún hermano atendido a través del sistema de protección, un $3 \%$ de ellos tiene más de cinco hermanos en esta situación.

No existe una gran incidencia de problemas sanitarios que les afectan, y en lo concerniente al sistema educativo están casi la mitad de ellos integrados con normalidad, aunque en un $28 \%$ existen transtornos de aprendizaje o retraso escolar. El mayor número de situaciones de maltrato o abandono son detectadas por el Equipo Social de Base $(48 \%)$, residiendo en un centro un amplio espectro de la muestra (el $72 \%$ en centros de acogida, el $15 \%$ en régimen de acogimiento familiar y el $13 \%$ con su familia de origen).

Pasando a analizar los tipos de maltrato más frecuentes, en los menores de nuestra provincia, podemos resumir que, aunque existe maltrato físico en un $28 \%$, lo que más se detecta es el abandono físico 
en un $73 \%$ de casos. Coincidimos con los estudios hechos con anterioridad, por autores ya citados, en el hecho de que el maltrato emocional, enmarcado tanto por las muestras de hostilidad verbal crónica, en forma de insulto, burla, desprecio, crítica o amenaza de abandono y/o constante bloqueo de las iniciativas infantiles, como por el vacio emocional creado por una persistente falta de respuestas paternas a las demandas de afecto y proximidad hechas por el menor, se observa, en un $41 \%$ de los casos, como el segundo en importancia. Esto último puede significar que se empieza a tener cierto control sobre el problema, existiendo, sin embargo, dificultad en su detección, posiblemente debido a las carencias de medios y recursos, tanto materiales como humanos disponibles en materia de prevención.

En cuanto a la aplicación de estos recursos, se debería estudiar si la Institucionalización del menor maltratado es la medida adecuada o si se debe potenciar otros recursos: acogimiento familiar o permanencia en su familia de origen en los casos que sea posible. En este aspecto, otros estudios ${ }^{5}$ concluyen que, en los programas incluidos dentro del Plan Integral de Protección de Menores de la Xunta de Galicia, es bastante significativo ver como medidas destinadas a potenciar un ambiente familiar normalizado, promoviendo la acción social a través de servicios que procuren que el menor permanezca en su ambiente familiar y comunitario, proporcionando las ayudas correspondientes, tienen un presupuesto netamente inferior a las que pretenden institucionalizar al menor.

Por lo tanto, y en resumen, es necesario potenciar la información y prevención dirigida a las familias afectadas por los problemas citados, además de las que presenten algunos de los factores de riesgo descritos. A su vez, es necesario una actuación inmediata e individualizada del menor, desarrollada por un equipo multidisciplinar, capaz de aplicar el recurso más adecuado a la problemática de cada uno de ellos y del modo más objetivo.

Y por último, creemos que es necesario promover el acogimiento bien dentro de la familia extensa del menor o en otra familia, pero siempre de la forma más normalizada posible, para lograr así una mejor adaptación del menor a su propio medio. 